\title{
LA GERONTOMIGRACIÓN: UNA PROPUESTA DE INVESTIGACIÓN GLOBAL PARA ABORDAR EL FENÓMENO COMPLEJO DE LA MOVILIDAD TRANSFRONTERIZA DE PERSONAS MAYORES
}

\author{
DIMENSIÓN JURÍDICA DE LAS RELACIONES \\ TRANSFRONTERIZAS DERIVADAS \\ DE LA GERONTOMIGRACIÓN
}

Mayte ECHEZARRETA FERRER*

Si el objetivo de este Foro es abordar un tema que afecte o vaya a afectar de manera directa o indirecta a las relaciones transfronterizas en España, la gerontomigración o movilidad transfronteriza de personas mayores ${ }^{1}$ es uno de ellos. Se trata de un fenómeno complejo ${ }^{2}$ que impacta en la estructura política, sanitaria, demográfica, ética, cultural, jurídica... e incluso en el diseño arquitectónico de la ciudad. Podemos decir que constituye por sí solo un laboratorio de investigación aplicada en temas relacionados con las Humanidades, las Ciencias de la Salud, las Ciencias Sociales y Jurídicas, la Ingeniería o la Arquitectura. El reto es poner a todas esas ciencias a dialogar y a construir propuestas eficientes, equilibradas y sostenidas, algo poco promocionado en nuestro país por la complejidad que supone romper el asignaturismo, por las exigencias de humildad y colaboración científica que exige y por el temor disciplinar a debilitar el control, difuminar los contornos o perder la identidad.

* Profesora titular de Derecho Internacional Privado. Universidad de Málaga (mtechezarret@uma. es). Todas las páginas web de referencia han sido consultadas por última vez el 26 de abril de 2018.

1 El concepto gerontoinmigrante fue acuñado en ECHEZARRETA FERRER, M. (dir.), El Lugar Europeo de Retiro. Indicadores de excelencia para administrar la gerontoinmigración de ciudadanos de la Unión Europea en municipios españoles, Granada, Comares, 2005.

2 Morin, E., Introducción al pensamiento complejo, Gedisa, 2009, http://grupal.reletran.org/wp-content/uploads/2013/09/MorinEdgar_Introduccion-al-pensamiento-complejo.pdf. Véase EcHEZARRETA FERRER, M., "La movilidad transfronteriza de las personas mayores: complejidad e interdisciplinariedad de la gerontoinmigración española», op. cit., nota 1, pp. 3-41. 
Desde 2001, en el seno de un grupo de investigación multidisciplinar ${ }^{3}$ y a través de diferentes proyectos ${ }^{4}$, investigadores de distintas áreas de conocimiento hemos ido contestando a algunas preguntas que nos planteaba el fenómeno, de forma disciplinar, interdisciplinar y transdisciplinar. Preguntas que, a su vez, hemos tratado de convertir en conclusiones transdisciplinares materializadas en forma de propuestas, algunas ejecutadas ${ }^{5} \mathrm{y}$ otras en fase de ejecución ${ }^{6}$. Durante estos años, hemos desarrollado actividades de investigación básica y aplicada, innovación y divulgación del conocimiento ${ }^{7}$, con un decidido objetivo de contribución al desarrollo del entorno cultural, social y económico de los lugares europeos de retiro, un número significativo de los cuales se localizan en España y, en particular, en el litoral mediterráneo, como explica Durán en este Foro. No olvidemos que se trata de un colectivo inversor, consumidor y contribuyente a las arcas del Estado, aunque, en ocasiones, pueda convertirse en una carga pública por falta de previsión política o por una deficiente gestión financiera por parte de las administraciones públicas.

Entre los colectivos que integran el fenómeno de la gerontomigración, el más relevante, conocido y estudiado es el de jubilados extranjeros que emigran para rentabilizar sus pensiones y vivir con mayor plenitud sus últimos años de vida. Sin embargo, y por la coincidencia de problemas e intereses, incluimos también a los inmigrantes, menos visibles de momento, aunque en aumento, que (una vez jubilados y sin adquirir la nacionalidad española) se quedan a residir en España, así como a los ascendientes extranjeros, reagrupados por inmigrantes laborales y a los retornados, emigrantes españoles que adquirieron o no la nacionalidad del país de acogida, e incluso sus descendientes, situación esta que se recrudecerá en el futuro con el retorno de los españoles que están abandonando el país en busca de trabajo y que vuelvan una vez jubilados. Las implicaciones sociodemográficas, ambientales, sanitarias, culturales y politológicas de la gerontoinmigración, que apunta Durán en este Foro, están sostenidas por una estructura jurídica no siempre coordinada ni

3 Grupo de investigación interdisciplinar consolidado del Plan Andaluz de Investigación (EURIE, SEJ-267), que coordiné desde 1989 a 2017, liderado en la actualidad por DuRÁn MuÑoz, R.

${ }_{4}$ Los proyectos que supusieron el origen y consolidación de nuestro trabajo fueron: (2002-2007), Acción Coordinada LJC/GGM de la Junta de Andalucía, participada por cuatro grupos de investigación: SEJ-171, SEJ-309, SEJ-347 y SEJ-267; (2007-2010), Proyecto de Excelencia Dirección General de Innovación, Ciencia y Empresa de la Junta de Andalucía (P06 -SEJ-01861); (2014-2015, UMA-FEDER), Proyecto-Puente para el Desarrollo de Proyectos de Investigación bajo el Marco del Programa de Fortalecimiento de las Capacidades en I+D+I en las Universidades, todos ellos coordinados por EcHEZARRETA FERRER, M. Los demás proyectos y redes de investigación en las que hemos participado hasta la fecha, pueden ser consultados en http://www.gerontomigracion.uma.es/index.php? $q=$ node/5.

5 Es el caso del Observatorio Europeo de Gerontomigraciones (OEG, disponible en $h t t p: / / w w w$. gerontomigracion.uma.es), entre cuyas actividades se encuentra la publicación de un boletín de prensa semanal o la publicación de boletines de investigación y comentarios cortos a noticias políticas o jurídicas relacionadas con el fenómeno. También, el diseño de parámetros de excelencia para los municipios que se postulen como lugares europeos de retiro (véase en http://www.gerontomigracion.uma.es/index. php?q=node/4).

6 Como la consolidación institucional de la credencial «Municipio LER», pendiente de tramitación, así como la conversión de dichos parámetros (véase nota 5) en indicadores evaluadores de la credencial.

7 En consonancia con la Ley 14/2011 de la Ciencia, BOE núm. 131, de 2 de junio de 2011. 
consciente del fenómeno. Sobre ella hemos venido estudiando, publicando y difundiendo nuestras conclusiones en foros de investigación y formación ${ }^{8}$ a lo largo de estos años, y que paso a mencionar en apretada síntesis.

El derecho que sustenta el fenómeno de la gerontomigración es el de circulación y, en particular, el derecho de residencia en España ${ }^{9}$. Derecho, cuyo disfrute no es incondicional, sino supeditado, en general, a la acreditación de un sustento económico y sanitario autónomo, ya se trate de ciudadanos de la UE o de nacionales de terceros Estados, aunque con límites diferentes. Ello conlleva, a su vez, la necesidad de importar, en la mayoría de los casos, las pensiones ${ }^{10} \mathrm{y}$ los derechos sanitarios ${ }^{11}$ generados en el extranjero, de origen privado o público, lo que, en este último caso, depende en la actualidad de reglamentos europeos de coordinación entre Estados miembros o de convenios con terceros Estados y, en el futuro y respecto del Reino Unido, del Acuerdo que está en gestación de 19 de marzo de $2018^{12}$. De aquí se puede deducir la falta de reflexión de muchos ciudadanos británicos movilizados para mantener la ciudadanía europea mediante la adquisición de la nacionalidad de un Estado miembro de la UE ${ }^{13}$ antes de que finalice el periodo transitorio del que nos informa Durán en este Foro. Y ello porque, aunque el ciudadano británico se convierta en español o irlandés, no podrá seguir manteniendo su residencia en España si no puede importar su pensión o sus derechos sanitarios cuando se dejen de aplicar dichos reglamentos. Sin embargo, si se llegara a un acuerdo al respecto, previsible al menos durante el periodo transitorio según el borrador de Acuerdo del que nos informa Durán, los británicos no tendrían problemas para seguir manteniendo la residencia en España, aunque se convirtieran en nacionales de terceros Estados al poder alcanzar fácilmente el estatuto de residentes permanentes. De aquí que, en el laboratorio del brexit, una de las prioridades si se apuesta por mantener el fenómeno, sea la movilidad de pensiones y de derechos sanitarios, pero no solo pensando en los británicos, sino también en los españoles que trabajan en Reino Unido, pues podrían decidir retornar a España tras su jubilación ${ }^{14}$. De momento, parece que los gerontoinmigrantes (GI) actuales, como los que decidan serlo

8 Véase la web del OEG.

9 Martín Martínez, M. y Jiménez SÁnchez, C. «La libre circulación de los residentes en la UE: especial referencia a los gerontoinmigrante de la Unión (UE)», en EchEZARRETA FERRER, M. (dir.), La residencia de los gerontoinmigrantes. Derechos y obligaciones de los jubilados extranjeros en los lugares europeos de retiro, Valencia, Tirant lo Blanch, 2016, pp. 59-89.

10 Lozano Lares, F., «Residencia y pensiones», op. cit., nota 9, pp. 131-163.

11 Álvarez González, E. M., «La prestación sanitaria transfronteriza. Supuestos, diferencias, similitudes y consecuencias», en Álvarez González, E. M., Sanidad transfronteriza y libertad de circulación. Un desafío para los lugares europeos de retiro, Valencia, Tirant lo Blanch, 2018, pp. 193-243.

12 http://www.gerontomigracion.uma.es/sites/default/files/usuarios/file/Documentos/draft_agreement_coloured.pdf.

13 Adquisición altamente complicada, por cierto, si se trata de cumplir los requisitos de la ley española de nacionalidad, aunque de momento no parecer ser la preferida. Véase «Sube un $165 \%$ la cifra de británicos que logran otra nacionalidad europea», Diario El País, 11 de abril de 2018, https://elpais. com/internacional/2018/04/11/actualidad/1523440110_156059.html.

14 Echezarreta Ferrer, M., "Incidencia del brexit en la movilidad transfronteriza de jubilados británicos. Algunas coincidencias con las relaciones hispano gibraltareñas», en MARTín MARTínEZ, M. 
durante el periodo transitorio, tendrán asegurados esos derechos. Del futuro no se ha hablado.

En aras de la integración, nos hemos ocupado, de un lado, del derecho al uso de la propia lengua en relación al Derecho Fundamental Europeo a la «buena administración». Y ello, por la constatación de que se trata de personas mayores que llegan a España en edad avanzada, con el deseo de descansar tras una larga vida laboral, sin estímulos ni siempre con habilidades suficientes para el aprendizaje, y que, sin embargo, requieren de una fluida relación con el entorno, tanto público como privado, para la gestión de sus intereses ${ }^{15}$. De otro lado, nos hemos ocupado también del estudio del ejercicio de los derechos políticos ${ }^{16}$, aunque no exista una especial inquietud por este derecho, como explica Durán en este Foro.

No cabe duda de que, junto con el sol, la seguridad, la cultura y la forma de vida mediterráneas, el asunto fiscal es otro de los mayores incentivos para la consolidación del destino España. La obligación desde 2013 de declarar las rentas o bienes en el exterior que superen los 50.000 euros, ligada a las fuertes sanciones que conlleva su incumplimiento (no obstante han sido suavizadas tras considerarlas desproporcionadas la Comisión Europea en su dictamen de 15 de febrero de 2017), condiciona a muchos la elección de España para invertir en su proyecto de jubilación. Tampoco se les pasa desapercibido a los extranjeros el impuesto de sucesiones español, sobre el que se pronunció el TJUE el 3 de septiembre de 2014 (as. C-127/12, ECLI:EU:C:2014:2130) declarando incompatible con la normativa europea la norma interna española discriminadora entre residentes y no residentes en España, y que, a la postre, ha resultado ilegal ${ }^{17}$. Este asunto está detrás del «sub registro» de algunos ciudadanos ${ }^{18}$, así como de numerosas estafas en forma de productos financieros que se publicitan como vía para reducir impuestos a los herederos y que han llevado a la ruina a extranjeros que confiaron en ellos ${ }^{19}$.

Los problemas de competencia judicial internacional, ley aplicable, reconocimiento y ejecución de resoluciones, así como de cooperación de autoridades, están presentes en cuantos asuntos de Derecho internacional privado (DIPR) afectan a los jubilados extranjeros que se encuentran en España. Pro-

\footnotetext{
y Martín y Pérez de NAnclares, J. (coords.), El Brexit y Gibraltar, Madrid, Ministerio de Asuntos Exteriores y Cooperación, 2017, pp. 239-261.

15 Rodríguez, Á., "No solo mis derechos. Lenguas comunitarias y administración local», en El Lugar Europeo de Retiro, op. cit., nota 1, pp. 117-192.

16 VVAA, "La participación política de los extranjeros en España», Revista Europea de Derechos Fundamentales, número extraordinario, primer semestre de 2016, 27. RodRíGuEz, Á. y Sánchez, P., «Residencia y derecho de participación», op. cit., nota 9, pp. 165-201.

17 García Calvente, Y., «Residencia y tributación. Especial referencia al colectivo de los gerontomigrantes», op. cit., nota 9, pp. 203-237. Véase STS (Sala de lo Contencioso, Sección 5), núm. 242/2018, de 19 de febrero, que rechaza también la discriminación respecto a extracomunitarios.

18 DurÁn MuÑoz, R., "Sanidad en la España de retiro: De atractivo para la gerontomigración a preocupación y movilización política por el brexit», op. cit., nota 11, pp. 29-57.

19 De tales noticias damos cuenta en nuestro Boletín OEG de Prensa, disponible en la web del Observatorio.
} 
blemas que, sin ser exclusivos de estos colectivos, sí son los más frecuentes. Me refiero, en primer lugar, a los relacionados con los contratos de compraventa de vivienda, préstamos y garantías hipotecarias, así como a la determinación del régimen económico matrimonial al adquirir el inmueble. El incumplimiento del pago del préstamo, de los suministros, de los gastos de la comunidad de propietarios, etc., junto con las ejecuciones hipotecarias tras la desaparición o vuelta de los deudores a su país de origen, a cuyo retorno alude Durán, son escenarios de este complejo fenómeno a los que le hemos dedicado especial atención analítica y propositiva a través de diferentes encuentros académicos ${ }^{20}$.

El divorcio entre los cónyuges y la división del patrimonio respecto de bienes que se encuentren en España son también problemas que se suceden periódicamente. Es frecuente que el divorcio se haya planteado en los países de origen y que el objeto del reconocimiento sea tan solo la modificación registral de la titularidad de los bienes de cuya problemática da cuenta la Dirección General de los Registros y del Notariado en numerosas resoluciones. Dentro del ámbito familiar, se debe apuntar también que este colectivo no plantea problemas de responsabilidad parental respecto a sus hijos por razones obvias de edad, pero sí respecto a sus nietos cuando las autoridades de origen, en particular las alemanas, nombran tutores a los abuelos y estos son residentes en España; surgen entonces problemas que no encajan en el actual Reglamento núm. 2201/2003 del Consejo, de 27 de noviembre, relativo a la competencia, el reconocimiento y la ejecución de resoluciones judiciales en materia matrimonial y de responsabilidad parental (Bruselas II bis) ${ }^{21}$ y que se están teniendo en cuenta en la reforma ${ }^{22}$ que nos disponemos a estudiar en un nuevo proyecto de investigación.

Nos ha llamado también la atención, aunque son imaginables las razones, que los GI en situación de vulnerabilidad y desamparo no demanden el pago de las deudas alimenticias a los ex cónyuges ni a los hijos. Esta es una de las preguntas que nos hacemos en el proyecto de investigación que acabamos de solicitar. Investigaremos, además de los problemas de la dependencia de los mayores extranjeros y de la asistencia sanitaria transfronteriza en los momentos brexit que vivimos, los problemas de DIPR relacionados con la reclamación de los alimentos por los acreedores y la ejecución de las resoluciones frente a los deudores. Y junto a ello, abordaremos las vías para que la Administración española se subrogue en los derechos de los extranjeros mayores vulnerables, atendidos en España gratuitamente en sus necesidades más básicas y, a la vez, acreedores de pensiones de alimentos respecto a sus parientes.

\footnotetext{
20 De las que hay cumplida información en el acceso correspondiente de la web del Observatorio.

21 Reglamento (CE) núm. 2201/2003 del Consejo, de 27 de noviembre, relativo a la competencia, el reconocimiento y la ejecución de resoluciones judiciales en materia matrimonial y de responsabilidad parental, DO L núm. 338, de 23 de diciembre de 2003.

22 Propuesta de Reglamento del Consejo modificando el R. 2201/2003/CE en materia de competencia y estableciendo normas relativas a la ley aplicable en materia matrimonial, de 30 de junio de 2016.
} 
En este ámbito de vulnerabilidad, también llama la atención que España no haya ratificado el Convenio de La Haya de 2000 sobre Protección de Adultos, ya que sería un buen instrumento de colaboración entre las autoridades de origen, en especial Reino Unido y Alemania, y España, para trabajar eficazmente en la protección de la dignidad de las personas vulnerables, y unificar las normas de DIPR, en materia de protección de mayores y, en especial, respecto a los apoderamientos preventivos huérfanos de una normativa unificada ${ }^{23}$.

Otra de las materias de especial relevancia entre los GI, es el Derecho sucesorio, donde la professio iuris alcanza su máxima expresión, en particular respecto a testadores británicos. Los temas para la investigación son numerosos. De momento, nos hemos encargado de estudiar la determinación del concepto de residencia habitual del Reglamento núm. 650/2012, del Parlamento Europeo y del Consejo, de 4 de julio de 2012, relativo a la competencia, la ley aplicable, el reconocimiento y la ejecución de las resoluciones, a la aceptación y la ejecución de los documentos públicos en materia de sucesiones mortis causa y a la creación de un certificado sucesorio europeo ${ }^{24}$, a efectos de la ley aplicable y su incidencia en la competencia judicial internacional a la luz de los datos empíricos de los que disponemos tras las encuestas que hemos realizado y de cuyos datos Durán da cumplida cuenta. Concepto, como sabemos, difícil de determinar en general en un mundo en constante movimiento, y más, respecto de personas que viven entre dos países, según la época del año y según los asuntos familiares, patrimoniales o de salud que deban solucionar en el de origen. A dicha vinculación jurídica le hemos dedicado una monografía, en la que estudiamos el concepto jurídico «residencia» desde el punto de vista de las obligaciones fiscales, de los derechos de pensiones, la asistencia sanitaria y la participación política, además de los registros públicos de extranjeros y de empadronamiento y la conexión en materia de competencia judicial internacional y de ley aplicable ${ }^{25}$.

Finalmente, hemos abordado de forma global y monográfica los derechos derivados de la sanidad transfronteriza, no solo referido a la exportación de

23 Echezarreta Ferrer, M., «Gestión de la diversidad y de la pluriconexión jurídica. Respuesta del Derecho Internacional Privado español a la protección de los gerontoinmigrantes comunitarios (GIC) en situación de vulnerabilidad», op. cit., nota 1, pp. 335-395. En la misma obra, CARo GÁNDARA, R., «La protección de los adultos discapaces en Derecho comparado. Sistemas más representativos», pp. 303330. Véase la Resolución de 1 de junio de 2017, por la que el Parlamento pide a la Comisión que presente al Parlamento Europeo y al Consejo, antes del 31 de marzo de 2018, sobre la base del art. 81, apartado 2 TFUE, una propuesta de Reglamento destinada a reforzar la cooperación entre los Estados miembros y el reconocimiento y la ejecución de las decisiones sobre protección de adultos vulnerables y de los mandatos por incapacidad.

24 Reglamento núm. 650/2012, del Parlamento Europeo y del Consejo, de 4 de julio de 2012, relativo a la competencia, la ley aplicable, el reconocimiento y la ejecución de las resoluciones, a la aceptación y la ejecución de los documentos públicos en materia de sucesiones mortis causa y a la creación de un certificado sucesorio europeo, DO L núm. 201, de 27 de julio de 2012.

25 Echezarreta Ferrer, M., «La residencia habitual como criterio de determinación de la competencia judicial internacional en las relaciones civiles transfronterizas», op. cit., nota 9, pp. 239-275; en la misma obra, CARO GÁNDARA, R., «La residencia habitual como criterio de determinación de la ley aplicable a las relaciones privadas transfronterizas», pp. 281-318. 
los derechos entre administraciones que vimos antes, sino también respecto al reconocimiento de las recetas médicas, el copago y el reembolso de gastos a los extranjeros asegurados en España, pero asistidos por un Estado de la UE. No ha faltado una atención especial a la ausencia de un marco común de los derechos de los pacientes a nivel europeo, en particular, los derechos al final de la vida. Y, desde la perspectiva del DIPR, también se han estudiado las obligaciones civiles, contractuales o no, derivadas de la sanidad transfronteriza, pública y privada, porque no olvidemos que la sanidad, además de ser un derecho vinculado a la dignidad, también es, en tanto que servicio, un producto de mercado ${ }^{26}$.

Cada avance en el estudio de un nuevo problema nos abre otros horizontes de investigación y nos hace más conscientes de la necesidad de buscar más conocimiento en otras ramas del saber y de ofertar el nuestro para, entre todos, construir propuestas que permitan, faciliten y aun alienten la movilidad de personas, eso sí, de forma sostenida para los Estados y digna para los ciudadanos.

Palabras clave: gerontomigración, disciplinariedad, interdisciplinariedad, transdisciplinariedad, complex phenomenon, derecho, turismo residencial, migración internacional de retirados.

Keywords: gerontomigration, disciplinarity, interdisciplinary, cross-disciplinarity, complex phenomenon, law, residential tourism, international retirement migration.

26 Echezarreta Ferrer, M., «Justicia civil en las relaciones transfronterizas», op. cit., nota 11, pp. 355-406. 